\title{
Detection of group a streptococcal pharyngitis by quantitative PCR
}

\author{
Eileen M Dunne ${ }^{1 *}$, Julia L Marshall ${ }^{3}$, Ciara A Baker ${ }^{2}$, Jayne Manning ${ }^{1}$, Gena Gonis ${ }^{4}$, Margaret H Danchinn ${ }^{2,3}$,
} Pierre R Smeesters ${ }^{2,5}$, Catherine Satzke ${ }^{1,6}$ and Andrew C Steer ${ }^{2,7}$

\begin{abstract}
Background: Group A streptococcus (GAS) is the most common bacterial cause of sore throat. School-age children bear the highest burden of GAS pharyngitis. Accurate diagnosis is difficult: the majority of sore throats are viral in origin, culture-based identification of GAS requires 24-48 hours, and up to 15\% of children are asymptomatic throat carriers of GAS. The aim of this study was to develop a quantitative polymerase chain reaction (qPCR) assay for detecting GAS pharyngitis and assess its suitability for clinical diagnosis.

Methods: Pharyngeal swabs were collected from children aged $3-18$ years $(n=91)$ and adults $(n=36)$ located in the Melbourne area who presented with sore throat. Six candidate PCR assays were screened using a panel of reference isolates, and two of these assays, targeting speB and spy 1258 , were developed into qPCR assays. The qPCR assays were compared to standard culture-based methods for their ability to detect GAS pharyngitis. GAS isolates from culture positive swabs underwent emm-typing. Clinical data were used to calculate Mclsaac scores as an indicator of disease severity.
\end{abstract}

Results: Twenty-four of the 127 samples (18.9\%) were culture-positive for GAS, and all were in children (26\%). The speB qPCR had $100 \%$ sensitivity and 100\% specificity compared with gold-standard culture, whereas the spy1258 qPCR had $87 \%$ sensitivity and 100\% specificity. Nine different emm types were found, of which emm 89, 3, and 28 were most common. Bacterial load as measured by qPCR correlated with culture load. There were no associations between symptom severity as indicated by Mclsaac scores and GAS bacterial load.

Conclusions: The speB qPCR displayed high sensitivity and specificity and may be a useful tool for GAS pharyngitis diagnosis and research.

\section{Background}

Group A streptococcus (GAS; Streptococcus pyogenes) is the most common bacterial cause of pharyngitis. GAS pharyngitis is most common in school-age children, affecting approximately 1 in 10 children per year [1]. In addition to pain and discomfort, throat infection can lead to suppurative complications such as otitis media and peri-tonsillar abscess, and non-suppurative sequelae such as rheumatic fever. GAS pharyngitis is a costly disease to society due to medical care and absence from school. In the United States, it is estimated that GAS pharyngitis costs the community up to 500 million USD per year [2].

\footnotetext{
* Correspondence: eileen.dunne@mcri.edu.au

'Pneumococcal Research, Murdoch Childrens Research Institute, Parkville, VIC, Australia

Full list of author information is available at the end of the article
}

Although GAS pharyngitis is usually self-limiting, rapid and accurate detection is important, as early treatment with appropriate antibiotics is known to reduce symptom severity and duration, decrease transmission of the organism, and reduce the risk of acute rheumatic fever [3-6]. As most pharyngitis is viral in origin, accurate diagnosis can reduce the unnecessary use of antibiotics and potential development of antibiotic resistance $[7,8]$. However, accurate diagnosis of GAS pharyngitis is difficult for a number of reasons. First, diagnosis of GAS pharyngitis using clinical signs alone is unreliable; physicians miss up to $50 \%$ of GAS pharyngitis cases and identify $20-40 \%$ of non-GAS sore throat cases as requiring antibiotics [9]. A contributing factor to misdiagnosis is that clinical presentation of GAS pharyngitis is variable; for example, in a study in Egypt only $31 \%$ of children with GAS pharyngitis had purulent exudates observed 
on clinical examination [10]. The Centor score [11] and the McIsaac score [9] (a modified version of the Centor score that takes patient age into account) use a combination of history and examination findings to aid clinical diagnosis of GAS pharyngitis, improving sensitivity from $50 \%$ up to $85 \%$ overall and $97 \%$ in children. However, specificity remains poor (67\% in children) [9]. Second, the standard procedure for laboratory detection of GAS, culture on blood agar, typically requires $24-48$ hours. Third, many children are asymptomatic carriers of GAS, with the prevalence of GAS throat carriage estimated at $12 \%[12]$.

Since the 1980s, commercial rapid antigen detection tests (RADTs) have been available as a means of GAS detection. The advantage of rapid diagnostic tests is that they can be quickly performed in the physician's office. However, although RADTs have good specificity (>95\%), they often have reduced sensitivity $(\sim 85 \%)$ compared to culture [13,14]. Another method of GAS detection, polymerase chain reaction (PCR), typically has higher sensitivity $(>90 \%)$ and good specificity (>95\%) $[15,16]$. Real-time quantitative PCR (qPCR) assays provide information on bacterial cell density, which can be used to assess the limit of detection of other assays such as RADTs, and to address scientific questions such as the relationship between bacterial density and disease severity.

In this study, we screened six candidate PCR assays using reference isolates and examined the sensitivity and specificity of two qPCR assays for detecting GAS pharyngitis. We also investigated how clinical data related to GAS prevalence and bacterial load.

\section{Methods}

\section{Study participants}

This was a prospective observational study of patients aged 3 years and older presenting with acute sore throat to primary care over the winter/spring of 2011 and 2012 in metropolitan Melbourne (Victoria, Australia). Recruitment occurred at three suburban general practices and the emergency department of Melbourne's major tertiary pediatric hospital (Royal Children's Hospital). Exclusion criteria were: previous oral antibiotics within the last week or intramuscular benzathine penicillin in the last month, history of rheumatic heart disease or post streptococcal glomerulonephritis, hospitalization, immunosuppression, obvious alternate diagnosis (such as herpes gingivostomatitis or hand foot and mouth disease), language barrier or inability to give consent. Antibiotics were prescribed to patients at the discretion of the treating physician. Demographic information, clinical data and throat swabs were collected at presentation. Clinical data were used to calculate the McIsaac score for each patient [9].

\section{Sample collection, detection of GAS by culture, and emm-typing}

Two throat samples were obtained using standard methods [3], rubbed together to facilitate even distribution of bacteria, and transported to the Royal Children's Hospital laboratory within $48 \mathrm{~h}$ (stored at ambient temperature if processed the same day of collection and at $4^{\circ} \mathrm{C}$ if kept overnight). One swab was used for detection of GAS by culture as previously described [1], with streptococcal grouping performed with the Prolex Streptococcal Grouping Latex kit (Pro-Lab Diagnostics, Richmond Hill, Canada). GAS growth was scored as follows: rare $(<10 \beta-$ hemolytic colonies in the first quadrant only), $1+(\geq 10$ in the first quadrant only), $2+$ ( $\geq 10$ in the first and second quadrants only), $3+(\geq 10$ in the first, second, and third quadrants only), and $4+$ ( $\geq 10$ in all four quadrants). emmtyping was performed as described by the Centers for Disease Control and Prevention (http://www.cdc.gov/ncidod/ biotech/strep/protocol_emm-type.htm) with the following modifications: $500 \mathrm{nM}$ primer concentration, and PCR cycling conditions were a $5 \mathrm{~min}$ activation at $95^{\circ} \mathrm{C}$, followed by 30 cycles of amplification at $95^{\circ} \mathrm{C}$ for $15 \mathrm{~s}$, $46.6^{\circ} \mathrm{C}$ for $30 \mathrm{~s}$, and $72^{\circ} \mathrm{C}$ for $90 \mathrm{~s}$ and a final extension at $72^{\circ} \mathrm{C}$ for $10 \mathrm{~min}$.

\section{PCR on reference isolates}

Primer pairs shown in Table 1 were tested against a panel of reference isolates shown in Table 2, present in our culture collection or kindly provided by Prof. Roy RobinsBrowne, The University of Melbourne. Bacterial DNA was extracted from fresh overnight cultures using a DNeasy Blood and Tissue kit (Qiagen, Doncaster, Australia). PCRs were performed in $25 \mu \mathrm{l}$ reactions containing approximately $10 \mathrm{ng}$ genomic DNA, $0.125 \mathrm{U}$ Amplitaq Gold DNA Polymerase, 1X PCR Gold Buffer (Applied Biosystems, Mulgrave, Australia), $2.0 \mathrm{mM} \mathrm{MgCl} 2,400 \mathrm{nM}$ forward and reverse primers (Sigma-Aldrich, Sydney, Australia), and $200 \mu \mathrm{M}$ each deoxynucleoside triphosphate (Promega, Alexandria, Australia). PCR cycling conditions were an initial $5 \mathrm{~min}$ at $95^{\circ} \mathrm{C}$ step, followed by 35 amplification cycles of $95^{\circ} \mathrm{C}$ for $30 \mathrm{~s}, 64^{\circ} \mathrm{C}$ for $30 \mathrm{~s}$, and $72^{\circ} \mathrm{C}$ for $45 \mathrm{~s}$, and a final extension at $72^{\circ} \mathrm{C}$ for $7 \mathrm{~min}$. PCR products were examined by gel electrophoresis.

Primer and dual-labeled probe sequences for the speB and spy 1258 qPCR assays are shown in Table 1. qPCRs were performed on reference isolates in duplicate $25 \mu \mathrm{l}$ reactions containing approximately $0.4 \mathrm{ng}$ genomic DNA, $100 \mathrm{nM}$ forward and reverse primer, $150 \mathrm{nM}$ probe (Eurogentec, Seraing, Belgium), and 1X Brilliant III Ultra-Fast QPCR master mix (Agilent Technologies, Santa Clara, USA) on a Stratagene Mx3005 realtime PCR instrument with an initial activation of $95^{\circ} \mathrm{C}$ for $3 \mathrm{~min}$ followed by 35 cycles of $95^{\circ} \mathrm{C}$ for $20 \mathrm{~s}$ and $60^{\circ} \mathrm{C}$ for $20 \mathrm{~s}$. 
Table 1 PCR assays selected for screening reference isolates

\begin{tabular}{|c|c|c|c|}
\hline Target & Primer and probe sequences $\left(5^{\prime}-3^{\prime}\right)^{*}$ & Product size (nt) & Reference \\
\hline \multirow{4}{*}{ speB } & $\begin{array}{l}\text { 1F: GGTTCTGCAGGTAGCTCTCG } \\
\text { 1R: TGCCTACAACAGCACTTTGG }\end{array}$ & 346 & [17] \\
\hline & 2F: CTAAACCCTTCAGCTCTTGGTACTG & \multirow{3}{*}{77} & \multirow{3}{*}{ This study } \\
\hline & 2R: TTGATGCCTACAACAGCACTITG & & \\
\hline & probe: Cy3-CGGCGCAGGCGGCTTCAAC-BHQ2 & & \\
\hline parE & $\begin{array}{l}\text { 1F: CAACAGATGCTACGGGATTGCAC } \\
\text { 1R: GTCAGTGTGGCAGATAGCGGACG }\end{array}$ & 139 & [18] \\
\hline \multirow{5}{*}{ spy 1258} & 1F: AAAGACCGCCTTAACCACCT & \multirow{2}{*}{450} & \multirow{2}{*}{ [19] } \\
\hline & 1R: TGGCAAGGTAAACTTCTAAAGCA & & \\
\hline & 2F: ACCTCAAATTTCCGCAACTC & \multirow{3}{*}{141} & \multirow{3}{*}{ This study } \\
\hline & 2R: TGCTCTCAATACTGGCAAGG & & \\
\hline & probe: Cy3-TGGTTTCCAAGACATTGTGACCAATCA-BHQ2 & & \\
\hline \multirow{2}{*}{ spy 1857} & 1F: CCTGCACCTGACATTTCAAC & \multirow{2}{*}{155} & \multirow{2}{*}{ This study } \\
\hline & 1R: GAAGGTATTGAAGGCCGTGT & & \\
\hline
\end{tabular}

*probes used for quantitative PCR assays only.

qPCR validation on clinical samples

The swab used for qPCR was stored in STGG media [20] at $-80^{\circ} \mathrm{C}$ until use. Lysis and DNA extraction from a $100 \mu \mathrm{l}$ aliquot was performed as previously described [21]. qPCR reactions were performed in triplicate using $1 \mu \mathrm{l}$ of DNA in each qPCR assay as described above. DNA extracted from pure cultures of $S$. pyogenes IGL 6 was used for standard curves to calculate genome equivalents/ $\mu$ l of GAS. Bacterial load data are reported as CFU/ml (assuming one genome per Colony Forming Unit and a GAS genome size of $1.8 \mathrm{Mb})$.

Table 2 PCR and qPCR results for streptococcal reference isolates

\begin{tabular}{|c|c|c|c|c|c|c|c|c|}
\hline \multirow[b]{2}{*}{ Species and strain } & \multicolumn{6}{|c|}{ PCR assay* } & \multicolumn{2}{|c|}{ qPCR assay** } \\
\hline & speB(1) & $s p e B(2)$ & parE & spy $1258(1)$ & spy1258(2) & spy 1857 & $\begin{array}{l}\text { speB } \\
\text { ct value }\end{array}$ & $\begin{array}{l}\text { spy } 1258 \\
\text { ct value } \\
\end{array}$ \\
\hline S. pyogenes IGL 1 & + & + & - & + & + & + & 19.5 & 19.9 \\
\hline S. pyogenes IGL 6 & + & + & - & + & + & + & 21.1 & 20.2 \\
\hline S. pyogenes IGL 13 & + & + & - & + & + & + & 21.6 & 20.3 \\
\hline S. pyogenes IGL 165 & + & + & - & + & + & + & 21.2 & 20.4 \\
\hline S. pyogenes IGL 181 & + & + & $+\backslash$ & + & + & + & 19.5 & 19.6 \\
\hline S. pyogenes ATCC BAA-572 & + & + & $+\backslash$ & + & + & + & 21.1 & 20.7 \\
\hline S. pyogenes IRP 187 & + & + & - & + & + & + & 20.2 & 19.9 \\
\hline S. pyogenes 85RP187 & + & + & + & + & + & + & 21.1 & 20.0 \\
\hline S. mitis PMP933 & $+\backslash-$ & $+\backslash-$ & NS & $+\backslash-$ & $+\backslash-$ & $+\backslash$ & $\mathrm{No} C t$ & $\mathrm{No} C t$ \\
\hline S. mitis PMP934 & $+\backslash-$ & $+\backslash-$ & NS & $+\backslash-$ & $+\backslash-$ & $+\backslash$ & $\mathrm{No} C t$ & 34.8 \\
\hline S. mitis PMP16 & $+\backslash-$ & $+\backslash-$ & - & $+\backslash-$ & $+\backslash-$ & $+\backslash-$ & $\mathrm{No} C t$ & $\mathrm{No} C t$ \\
\hline S. pneumoniae ATCC 6305 & - & - & + & - & - & - & $\mathrm{No} C t$ & $\mathrm{No} C t$ \\
\hline S. agalactiae ATCC 13813 & - & - & NS & - & - & + & $\mathrm{No} C t$ & $\mathrm{No} C t$ \\
\hline S. agalactiae GBS78 & $+\backslash-$ & - & NS & - & $+\backslash-$ & + & $\mathrm{No} C t$ & $\mathrm{NoCt}$ \\
\hline S. agalactiae GBS79 & - & - & - & $+\backslash-$ & $+\backslash-$ & + & $\mathrm{No} C t$ & $\mathrm{No} C t$ \\
\hline S. sanguis NTCT7864 & - & - & NS & - & - & - & $\mathrm{No} C t$ & $\mathrm{No} C t$ \\
\hline S. mutans PMP935 & - & - & NS & - & - & + & $\mathrm{No} C t$ & $\mathrm{No} \mathrm{Ct}$ \\
\hline
\end{tabular}

${ }^{*}+=$ strong PCR product at expected size; $+/-=$ weak PCR product at expected size; NS = non-specific (PCR product at unexpected size and/or multiple PCR products); - = no PCR product.

** Cycle threshold $(\mathrm{Ct})$ values are reported as the mean of duplicate wells containing $0.4 \mathrm{ng}$ genomic DNA. 


\section{Statistical analysis}

Analyses were conducted using Prism 5.04 (GraphPad Software, Inc., La Jolla, USA). Student's t test were used to compare normally distributed data and MannWhitney and Kruskal-Wallis tests used for data that did not show normal distribution. The chi-square test for trend was used to assess GAS prevalence and McIsaac scores. Spearman's rank correlation coefficient was used to examine associations between bacterial loads by qPCR and plate growth scores and bacterial loads by qPCR and McIsaac scores. McIsaac scores and plate growth scores were examined using the Pearson correlation coefficient and chi-square test for trend. P values $<0.05$ were considered statistically significant.

\section{Ethical approval}

The study was performed in accordance with the Declaration of Helsinki and was approved by the Royal Children's Hospital Melbourne Human Research Ethics Committee HREC 31151 and 32080. Prior to enrolment in the study, informed consent was given by participants or by a parent/guardian for participants under the age of 18 .

\section{Results}

\section{Patient characteristics}

The 127 participants included 60 females and 67 males; 91 were children and 36 were adults. Ages ranged from 3 to 72 years with a mean age of $9 y$ for children and 38 y for adults.

\section{PCR on reference isolates}

The six primer pairs (Table 1) initially tested in our collection of reference streptococcal species (Table 2) targeted four GAS genes or genetic regions (speB, parE, spy 1258, and spy1857). For two target genes (speB and spy1258), published primers resulted in a product size larger than recommended for qPCR, so alternative primers generating a shorter product were designed and tested. Initial qualitative PCR revealed that the parE assay had limited sensitivity for GAS, whereas the spy1857 detected several non-group A streptococcal species (Table 2). S. mitis displayed some cross-reactivity for all assays tested. Based upon these results, two assays targeting speB (encoding a cysteine protease [22]) and spy1258 (encoding a putative transcriptional regulator [19]) were selected for qPCR assay development. The optimal number of qPCR cycles was determined to be 35 to avoid false positive results with $S$. mitis, S. sanguis or $S$. agalacticae. Only one isolate of $S$. mitis showed faint cross-reactivity for the spy1258 assay ( $\mathrm{Ct}$ of 34.8; Table 2). The limit of detection for both qPCR assays was 24 genome equivalents/ $\mu \mathrm{l}$, as this corresponded to the lowest value on the standard curve that consistently resulted in a $\mathrm{Ct}$ value $<35$.

\section{Culture and qPCR results from clinical samples}

Of the 127 throat samples analyzed, 24 (18.9\%) were positive for GAS by culture. All 24 positive samples came from children; therefore, the GAS-positive proportion in this age group was $26 \%$. A total of nine different emm types were identified, with emm89 (6 isolates), emm3 (5 isolates), emm 28 ( 4 isolates) the most common. Other emm types were emm12.0 (3 isolates), emm1 (2 isolates), and emm81, emm75, emm9, and emm87 (1 isolate each). Two new emm subtypes, emm3.87 and emm12.67, were discovered.

In comparison with culture results, the $s p e B$ qPCR had $100 \%$ sensitivity and specificity, whereas the spy 1258 qPCR had $87 \%$ sensitivity and $100 \%$ specificity (Table 3 ). None of three samples positive for either group $\mathrm{C}$ or $\mathrm{G}$ streptococci were positive with our qPCR assays. The three samples for which the spy 1258 qPCR gave a false negative result were from GAS type emm3 (two isolates) and emm 28 (one isolate) and the bacterial plate growth scores ranged from $1+$ to $3+$.

GAS loads were then estimated using speB qPCR. GAS bacterial loads ranged from $2.9 \times 10^{4}$ to $1.3 \times 10^{7}$ $\mathrm{CFU} / \mathrm{ml}$, with a mean of $1.1 \times 10^{6} \mathrm{CFU} / \mathrm{ml}$. GAS loads by $\mathrm{qPCR}$ positively correlated with plate growth scores (Figure 1A; $\mathrm{P}=0.01$ ).

\section{Symptom severity}

Overall, mean McIsaac scores were significantly higher for patients positive for GAS $(2.7,95 \% \mathrm{CI}: 2.3,3.1)$ than those who were GAS negative (1.6, 95\% CI: 1.4, 1.9). This is in keeping with recently published data from the United States (Table 4; [23]). Of note, there was no association between McIsaac score and bacterial loads as determined by qPCR (Figure $1 \mathrm{~B} ; \mathrm{P}=0.39$ ) or by plate growth score $(\mathrm{P}=0.08)$.

\section{Discussion}

In this study, we screened six qualitative PCR assays for GAS identification and selected two candidate qPCR assays, whose ability to detect GAS pharyngitis was compared to the current gold standard, culture of a throat swab on blood agar. The speB qPCR assay displayed 100\% sensitivity and specificity, and bacterial load data were consistent with semi-quantitative measurements of plate

\begin{tabular}{|c|c|c|c|c|c|}
\hline \multirow{2}{*}{$\begin{array}{l}\text { qPCR } \\
\text { assay }\end{array}$} & \multirow{2}{*}{$\begin{array}{l}\text { qPCR } \\
\text { result }\end{array}$} & \multicolumn{2}{|c|}{ Culture result } & \multirow{2}{*}{$\%$ sensitivity* } & \multirow{2}{*}{$\%$ specificity* } \\
\hline & & + & - & & \\
\hline \multirow{2}{*}{ speB } & + & 24 & 0 & \multirow{2}{*}{$100(88,100)$} & \multirow{2}{*}{$100(96,100)$} \\
\hline & - & 0 & 103 & & \\
\hline \multirow{2}{*}{ spy 1258} & + & 21 & 0 & \multirow{2}{*}{$87(68,96)$} & \multirow{2}{*}{$100(96,100)$} \\
\hline & - & 3 & 103 & & \\
\hline
\end{tabular}

* 95\% confidence intervals (Wald method) shown in parentheses. 

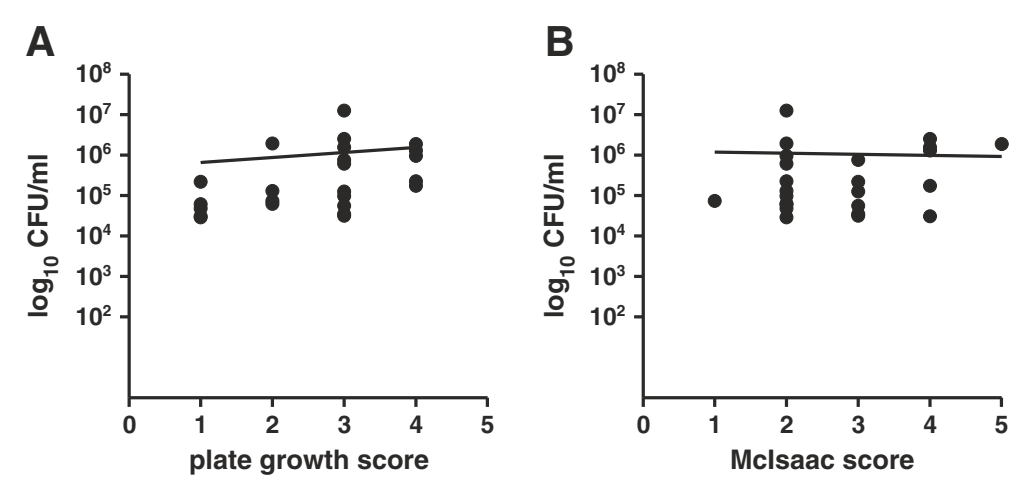

Figure 1 GAS bacterial loads, plate growth, and symptom severity (Mclsaac score). (A). GAS bacterial loads as determined by speB qPCR by plate growth score. $P=0.01$. (B). GAS bacterial loads as determined by speB $q P C R$ by Mclsaac score. $P=0.39$. For both $\mathbf{A}$ and $\mathbf{B}$, each data point represents CFU/ml data from one patient. Nonlinear regression curves are shown in black and P values calculated using Spearman's correlation test.

growth. It is unclear why spy 1258 had lower sensitivity, as the failure to detect three GAS isolates appears unrelated to bacterial load or emm type. However, no internal control for PCR inhibition was used, so it is possible that inhibition may have contributed to the reduced sensitivity of the spy 1258 assay. Although the speB qPCR had excellent sensitivity and specificity, this assay would require further optimization to be used as a rapid diagnostic tool given the current lengthy DNA extraction protocol (optimized to maximize DNA yields). The LightCycler PCR assay for GAS detection was developed as a diagnostic tool [16], but unlike the speB qPCR assay described here, it is not typically performed with a standard curve and does not provide quantitative data on bacterial loads.

Differentiation between acute GAS pharyngitis and pharyngeal carriage remains a challenge and further studies should include asymptomatic carriers. Potential differences in bacterial load between GAS carriage and GAS infection could be evaluated using speB qPCR in a larger, population-based study. It is likely that other differences between the carrier and infective state, such as host response or presence of virulence factors, will also be important. In this study, we did not see a correlation between symptom severity as indicated by McIsaac

Table 4 Distribution of Mclsaac scores and positive GAS results

\begin{tabular}{|c|c|c|c|}
\hline $\begin{array}{l}\text { Mclsaac } \\
\text { score }\end{array}$ & $\begin{array}{l}\text { Total } \\
\text { n (\%)* }\end{array}$ & $\begin{array}{l}\text { GAS positive } \\
\text { n (\%) }\end{array}$ & $\begin{array}{l}\text { Estimated risk of GAS } \\
\text { (\%) [23] }\end{array}$ \\
\hline$\leq 0$ & $25(20)$ & $0(0)$ & $8-9$ \\
\hline 1 & $22(17)$ & $1(4)$ & $13-14$ \\
\hline 2 & $40(31)$ & $11(27)$ & $23-23$ \\
\hline 3 & $27(21)$ & $6(22)$ & $37-37$ \\
\hline$\geq 4$ & $13(10)$ & $6(46)$ & $55-56$ \\
\hline
\end{tabular}

* \% of total patients with the corresponding Mclsaac score.

$+\%$ of patients with the corresponding Mclsaac score who were GAS positive. score and GAS bacterial load as determined by qPCR or by plate growth scores. Although variation in throat swabbing techniques can impact the ability to evaluate bacterial loads, in this study, all samples were collected in a consistent manner by two trained co-investigators. A recent report by Cohen et al. [24] suggested that heavier plate growth was associated with a trend towards higher McIsaac scores in children with pharyngitis. However, the reported $\mathrm{P}$ value was 0.09 and plate growth scored as either heavy (3+) or light (1+ and $2+)$. In another study by the same group that included asymptomatic children, throat swabs from asymptomatic carriers of GAS were less likely to have heavy plate growth than swabs from children with GAS pharyngitis [25]. The link between lower bacterial load and the carrier state should be further investigated by quantitative methods such as the speB qPCR. This assay may also help in assessing whether RADT-negative, culture-positive children may represent GAS carriers.

The proportion of children with sore throat with a GAS positive culture in our study (26\%) is within the $15-30 \%$ range typically reported [26] and is similar to earlier studies performed in metropolitan Melbourne $[1,27]$. The emm types identified were also similar to those reported in a previous study in Melbourne [1] and are among those most common in high-income countries $[28,29]$.

\section{Conclusions}

This study identified $s p e B$ qPCR as a highly sensitive and specific assay for detecting GAS in throat swabs. The assay may be useful as a diagnostic tool in the future, allowing accurate identification of patients with GAS sore throat. In addition, further investigation into the relationship between bacterial load as determined by $\mathrm{qPCR}$ and GAS pharyngeal infection, or carriage, is warranted. 


\section{Competing interests}

Sample collection was initially funded in part by Quidel Corporation as part of a separate project to evaluate a commercial RADT. However, the RADT project was discontinued and Quidel Corporation had no involvement with the current study.

\section{Authors' contributions}

EMD participated in study design, carried out qPCR, performed statistical analysis, and drafted the manuscript. JLM carried out sample collection, participated in study design, and helped draft the manuscript. CAB carried out sample collection and study coordination. JM designed and performed PCR assays and assisted in qPCR optimization. GG participated in protocol design and oversaw diagnostics by culture. MHD participated in study design and coordination. PRS and CS participated in study design and edited the manuscript. ACS conceived of the study, oversaw its design and coordination, and edited the manuscript. All authors read and approved the final manuscript.

\section{Acknowledgements}

This work was supported by funding from the Murdoch Childrens Research Institute, Quidel Corporation, and the Victorian Government's Operational Infrastructure Support Program. Julia Marshall received funding from the Australian General Practice Education and Training Limited. We thank all study participants and the medical staff from the Royal Children's Hospital Emergency Department, Whittlesea Family Medical Centre, Childs Road Medical Centre Mill Park, and the Nepean Family Medical Centre. We thank Leisha Richardson, Rebecca Towers and Peter Fagan for providing details of the speB qPCR assay that was developed at Menzies School of Health Research. We acknowledge Melisa Gauci, Abdullateef Alshehri, and Anna Phillips for assistance with laboratory work, and Jacqui Williams for patient recruitment.

\section{Author details}

${ }^{1}$ Pneumococcal Research, Murdoch Childrens Research Institute, Parkville, VIC, Australia. 'roup A Streptococcus, Murdoch Childrens Research Institute, Parkville, VIC, Australia. ${ }^{3}$ Department of Paediatrics, The University of Melbourne, Parkville, VIC, Australia. ${ }^{4}$ Microbiology, Department of Laboratory Services, Royal Children's Hospital, Parkville, VIC, Australia. ${ }^{5}$ Laboratoire de Génétique et Physiologie Bactérienne, Institut de Biologie et de Médecine Moléculaires, Faculté des Sciences, Université Libre de Bruxelles, Gosselies, Belgium. 'Department of Microbiology and Immunology, The University of Melbourne, Parkville, VIC, Australia. ${ }^{7}$ Centre for International Child Health, The University of Melbourne, Parkville, VIC, Australia.

Received: 8 February 2013 Accepted: 25 June 2013

Published: 11 July 2013

\section{References}

1. Danchin MH, Rogers S, Kelpie L, Selvaraj G, Curtis N, Carlin JB, Nolan TM, Carapetis JR: Burden of acute sore throat and group A streptococcal pharyngitis in school-aged children and their families in Australia. Pediatrics 2007, 120(5):950-957.

2. Pfoh E, Wessels MR, Goldmann D, Lee GM: Burden and economic cost of group A streptococcal pharyngitis. Pediatrics 2008, 121(2):229-234.

3. Shulman ST, Bisno AL, Clegg HW, Gerber MA, Kaplan EL, Lee G, Martin JM, Van Beneden C: Clinical practice guideline for the diagnosis and management of group A streptococcal pharyngitis: 2012 update by the Infectious Diseases Society of America. Clin Infect Dis 2012, 55(10):1279-1282.

4. Choby BA: Diagnosis and treatment of streptococcal pharyngitis. Am Fam Physician 2009, 79(5):383-390.

5. Zwart S, Sachs AP, Ruijs GJ, Gubbels JW, Hoes AW, Melker RA: Penicillin for acute sore throat: randomised double blind trial of seven days versus three days treatment or placebo in adults. BMJ 2000, 320(7228):150-154.

6. Gerber MA, Baltimore RS, Eaton CB, Gewitz M, Rowley AH, Shulman ST, Taubert KA: Prevention of rheumatic fever and diagnosis and treatment of acute streptococcal pharyngitis: a scientific statement from the American Heart Association Rheumatic Fever, Endocarditis, and Kawasaki Disease Committee of the Council on Cardiovascular Disease in the Young, the Interdisciplinary Council on Functional Genomics and Translational Biology, and the Interdisciplinary Council on Quality of
Care and Outcomes Research: Endorsed by the American Academy of Pediatrics. Circulation 2009, 119(11):1541-1551.

7. Smeesters PR, Campos D Jr, Van Melderen L, De Aguiar E, Vanderpas J, Vergison A: Pharyngitis in low-resources settings: a pragmatic clinical approach to reduce unnecessary antibiotic use. Pediatrics 2006, 118(6):e1607-e1611.

8. Joachim L, Campos D Jr, Smeesters PR: Pragmatic scoring system for pharyngitis in low-resource settings. Pediatrics 2010, 126(3):e608-e614.

9. Mclsaac WJ, White D, Tannenbaum D, Low DE: A clinical score to reduce unnecessary antibiotic use in patients with sore throat. CMAJ 1998, 158(1):75-83.

10. Steinhoff MC, Abd el Khalek MK, Khallaf N, Hamza HS, Ayadi AE, Orabi A, Fouad $H$, Kamel M: Effectiveness of clinical guidelines for the presumptive treatment of streptococcal pharyngitis in Egyptian children. Lancet 1997, 350(9082):918-921.

11. Centor RM, Witherspoon JM, Dalton HP, Brody CE, Link K: The diagnosis of strep throat in adults in the emergency room. Med Decis Making 1981, 1(3):239-246.

12. Shaikh N, Leonard E, Martin JM: Prevalence of streptococcal pharyngitis and streptococcal carriage in children: a meta-analysis. Pediatrics 2010, 126(3):e557-e564.

13. Gerber MA, Shulman ST: Rapid diagnosis of pharyngitis caused by group A streptococci. Clin Microbiol Rev 2004, 17(3):571-580.

14. Rimoin AW, Walker CL, Hamza HS, Elminawi N, Ghafar HA, Vince A, Da Cunha AL, Qazi S, Gardovska D, Steinhoff MC: The utility of rapid antigen detection testing for the diagnosis of streptococcal pharyngitis in low-resource settings. Int J Infect Dis 2010, 14(12):e1048-e1053.

15. Slinger R, Goldfarb D, Rajakumar D, Moldovan I, Barrowman N, Tam R, Chan F: Rapid PCR detection of group A streptococcus from flocked throat swabs: a retrospective clinical study. Ann Clin Microbiol Antimicrob 2011, 10(1):33.

16. Uhl JR, Adamson SC, Vetter EA, Schleck CD, Harmsen WS, Iverson LK, Santrach PJ, Henry NK, Cockerill FR: Comparison of LightCycler PCR, rapid antigen immunoassay, and culture for detection of group A streptococci from throat swabs. J Clin Microbiol 2003, 41(1):242-249.

17. McMillan DJ, Vu T, Bramhachari PV, Kaul SY, Bouvet A, Shaila MS, Karmarkar MG, Sriprakash KS: Molecular markers for discriminating Streptococcus pyogenes and S. dysgalactiae subspecies equisimilis. Eur J Clin Microbiol Infect Dis 2010, 29(5):585-589.

18. Roth SB, Jalava J, Ruuskanen O, Ruohola A, Nikkari S: Use of an oligonucleotide array for laboratory diagnosis of bacteria responsible for acute upper respiratory Infections. J Clin Microbiol 2004, 42(9):4268-4274.

19. Liu D, Hollingshead S, Swiatlo E, Lawrence ML, Austin FW: Rapid identification of Streptococcus pyogenes with PCR primers from a putative transcriptional regulator gene. Res Microbio/ 2005, 156(4):564-567.

20. O'Brien KL, Bronsdon MA, Dagan R, Yagupsky P, Janco J, Elliott J, Whitney CG, Yang YH, Robinson LG, Schwartz B, Carlone GM: Evaluation of a medium (STGG) for transport and optimal recovery of Streptococcus pneumoniae from nasopharyngeal secretions collected during field studies. J Clin Microbio/ 2001, 39(3):1021-1024.

21. Dunne EM, Manning J, Russell FM, Robins-Browne RM, Mulholland EK, Satzke C: Effect of pneumococcal vaccination on nasopharyngeal carriage of Streptococcus pneumoniae, Haemophilus influenzae, Moraxella catarrhalis, and Staphylococcus aureus in Fijian children. J Clin Microbiol 2012, 50(3):1034-1038.

22. Hauser AR, Schlievert PM: Nucleotide sequence of the streptococcal pyrogenic exotoxin type $B$ gene and relationship between the toxin and the streptococcal proteinase precursor. J Bacteriol 1990, 172(8):4536-4542.

23. Fine AM, Nizet V, Mandl KD: Large-scale validation of the Centor and Mclsaac scores to predict group A streptococcal pharyngitis. Arch Intern Med 2012, 172(11):847-852

24. Cohen JF, Chalumeau M, Levy C, Bidet P, Thollot F, Wollner A, Bingen E, Cohen R: Spectrum and inoculum size effect of a rapid antigen detection test for group A Streptococcus in children with pharyngitis. PLOS One 2012, 7(6):e39085.

25. Cohen JF, Chalumeau M, Levy C, Bidet P, Benani M, Koskas M, Bingen E, Cohen R: Effect of clinical spectrum, inoculum size and physician characteristics on sensitivity of a rapid antigen detection test for group A streptococcal pharyngitis. Eur J Clin Microbiol Infect Dis 2013, 32(6):787-793. 
26. Ebell MH, Smith MA, Barry HC, Ives K, Carey M: The rational clinical examination. Does this patient have strep throat? JAMA 2000, 284(22):2912-2918.

27. Edmond KM, Grimwood K, Carlin JB, Chondros P, Hogg GG, Barnett PL: Streptococcal pharyngitis in a paediatric emergency department. Med J Aust 1996, 165(8):420-423.

28. Steer AC, Law I, Matatolu L, Beall BW, Carapetis JR: Global emm type distribution of group A streptococci: systematic review and implications for vaccine development. Lancet Infect Dis 2009, 9(10):611-616.

29. Smeesters PR, McMillan DJ, Sriprakash KS, Georgousakis MM: Differences among group A streptococcus epidemiological landscapes: consequences for M protein-based vaccines? Expert Rev Vaccines 2009, 8(12):1705-1720.

doi:10.1186/1471-2334-13-312

Cite this article as: Dunne et al:: Detection of group a streptococcal pharyngitis by quantitative PCR. BMC Infectious Diseases 2013 13:312.

\section{Submit your next manuscript to BioMed Central and take full advantage of:}

- Convenient online submission

- Thorough peer review

- No space constraints or color figure charges

- Immediate publication on acceptance

- Inclusion in PubMed, CAS, Scopus and Google Scholar

- Research which is freely available for redistribution 